\title{
Thin Layer Drying Kinetics of Solar-Dried Amaranthus hybridus and Xanthosoma sagittifolium Leaves
}

\section{P.T. Akonor ${ }^{1 *}$ and E.A. Amankwah ${ }^{2}$}

${ }^{1}$ P.T. Akonor, Food Processing and Engineering Division, CSIR - Food Research Institute, P.O. Box M30, Accra, Ghana ${ }^{2}$ Department of Biochemistry and Biotechnology, Kwame Nkrumah University of Science and Technology, Kumasi

\begin{abstract}
The aim of the study was to model the solar drying characteristics of the leaves of Amaranthus hybridus and Xanthosoma sagittifolium dried in thin layers. Fresh leaves were obtained from Centre for Biodiversity Utilisation and Development (CBUD) farms, trimmed into strips of $0.3 \mathrm{~cm} \times 3 \mathrm{~cm}$ and loaded into cabinet solar dryers up to a $5 \mathrm{~mm}$ layer. Drying was monitored and moisture loss was determined by loss in weight of samples at hourly interval. Drying data were fitted to five thin layer models, namely; Newton's, Page's, Modified Page, Handerson and Pabis and Logarithmic models by Non-linear Regression Analysis, the effective diffusivity was also determined for the two leafy vegetables. All five models showed a good fit between observed and predicted values, with Page's model resulting in the highest $\mathrm{r}^{2}$ and lowest RMSE and $X^{2}$ and hence the best model to describe the solar-drying characteristics of the two vegetables.
\end{abstract}

Keywords: Drying curves; Effective Moisture Diffusivity; Leafy vegetables; Mathematical modelling; Solar drying

\section{Nomenclature:}

$\mathrm{a}, \mathrm{b}, \mathrm{c}, \mathrm{k}, \mathrm{y}$
$\mathrm{D}_{\text {eff }}$
$\mathrm{L}$
$\mathrm{MR}$
$\mathrm{M}$
$\mathrm{Mo}$
$\mathrm{N}$
$\mathrm{r}^{2}$
$\mathrm{t}$
$\mathrm{z}$
$\exp$

Constants in models

Effective diffusivity

Half-thickness of slab

$\mathrm{m}^{2} / \mathrm{s}$

Moisture ratio

Moisture content

Initial moisture content

Number of observation

Coefficient of determination

Drying time

$\min$

Number of constants

pre Predicted

\section{Introduction}

Leafy vegetables have gained commercial importance and form an essential part of the Ghanaian diet, providing vitamins and micronutrients. As a result of their high moisture and short shelf life, there is the need to process them into stabilized forms with controlled water activity [1] that can store for longer periods [2] so that they will be available all year round [3]. Drying presents one of the most effective methods of food preservation. The process broadly describes the thermal removal of moisture from a product to yield a solid product [4]. It is a dual process of heat transfer to the product from the heating source and the mass transfer of moisture from the interior of the product to its surface and from the surface to the surrounding environment [5] and therefore the rate at which drying proceeds depends primarily on the rate at which these two processes proceed [4].

Drying method and the physical and biochemical changes that occur during drying seem to affect the quality properties of the dehydrated product. The proper handling of these reactions ensures that the dried product has a high nutritional value as well as a significantly extended shelf life. It is, therefore, essential to model and study the drying characteristics of food products in order to predict the suitable drying conditions as part of process control [6] and in the design and manufacture of dryers.

The study aimed at observing the drying characteristics of solardried Amaranthus spp and Xanthosoma spp leaves in thin layers using five analytical models in order to ascertain the model which best describes these drying characteristics.

\section{Material and Methods}

\section{Drying experiments}

Fresh fully mature and edible Amaranthus spp (months) and Xanthosoma spp leaves were obtained from the Centre for Biodiversity Utilisation and Development (CBUD) farms at the Amanfrom Prison Camp in Kumasi. The leaves were detached from their stalks and inedible parts removed. The leaves were washed and trimmed into thin strips of dimension $(0.3 \times 3 \mathrm{~cm})$ spread evenly on drying trays and loaded into a solar cabinet dryer (made of wood with glass windows, schematic in Figure 1 at a density of $1.5 \mathrm{~kg} / \mathrm{m}^{2}$, in a single layer of $5 \mathrm{~mm}$. Moisture loss during drying was determined by measuring the loss in weight of samples at hourly interval and at the beginning and end of drying and the representative samples are then taken for moisture content determination [7]. The leaves, with initial moisture (wb) content $85.8 \%$ and $82.7 \%$, were dried to a final moisture content of $8.5 \%$ and $8.9 \%$ for Amaranthus spp and Xanthosoma spp leaves respectively. Average drying temperatures over the period of drying in the dryers were $49.8^{\circ} \mathrm{C}$ (RH $31.3 \%$ ) and $48.7^{\circ} \mathrm{C}$ (RH 32.8) (Thermo hygrometer, Hanna HI 91610) for Amaranthus spp and Xanthosoma spp respectively. In

${ }^{*}$ Corresponding author: P.T. Akonor, Food Processing and Engineering Division, CSIR - Food Research Institute, P. O. Box M30, Accra, Ghana, E-mail: papatoah@gmail.com

Received June 11, 2012; Accepted July 23, 2012; Published July 27, 2012

Citation: Akonor PT, Amankwah EA (2012) Thin Layer Drying Kinetics of SolarDried Amaranthus hybridus and Xanthosoma sagittifolium Leaves. J Food Process Technol 3:174. doi:10.4172/2157-7110.1000174

Copyright: (c) 2012 Akonor PT, et al. This is an open-access article distributed under the terms of the Creative Commons Attribution License, which permits unrestricted use, distribution, and reproduction in any medium, provided the original author and source are credited. 
order to reduce the incidence of moisture reabsorption, drying was discontinued at sundown $\left(30.1^{\circ} \mathrm{C}, \mathrm{RH} 47.5 \%\right.$ and $30.8^{\circ} \mathrm{C} \mathrm{RH} 46.3 \%$ for Amaranthus spp and Xanthosoma spp respectively) and the products were sealed air-tight in polypropylene bags overnight and drying continued the next morning (ambient $24.9^{\circ} \mathrm{C}$, RH $69.8 \%$ ).

\section{Model fitting of drying data}

Drying data was fitted to the Newton's, Page's, Modified Page, Handerson and Pabis and Logarithmic models by Non-linear Regression Analysis (STATGRAPHICS Centurion, 15.1) and coefficient of correlation and goodness of fit of predicted to experimental data determined. The moisture ratio was simplified as $M / M_{0}$ because the relative humidity of the inlet air could not be controlled and $\mathrm{M}_{\mathrm{e}}$ is very small as compared to $\mathrm{M}_{\mathrm{o}}$. (Table 1 )

The reduced chi square was calculated as:

$$
\chi 2=\frac{\sum_{i=1}^{N}(M \operatorname{Re} x p, i-M R p r e, i) 2}{N-z}
$$

\section{Effective moisture diffusivity}

During drying, a general diffusion transport mechanism in which the rate of moisture movement is described by an effective diffusivity value, $D_{\text {eff }}$ is often assumed, regardless of which mechanism is really involved in moisture movement. In this approach, Fick's diffusion equation is used to explain the effective diffusivity. Parameters required in this approach are only sample dimensions and the effective diffusion coefficient. This method is very practical and convenient in describing moisture content change during processing. In using Fick's equation, the leaves used were assumed as slabs and all assumptions for slabshaped objects were proposed by [8] observed. The effective diffusivity was calculated by a linearised version [9-11].

$$
\ln (M R)=\ln \left(\frac{8}{\pi 2}\right)-\left(\frac{D e f f \times \pi 2}{4 L 2} \times t\right)
$$

Where, $D_{\text {eff }}$ is the effective diffusivity $\left(\mathrm{m}^{2} / \mathrm{s}\right)$; $\mathrm{L}$ is half the thickness of the slab (m).

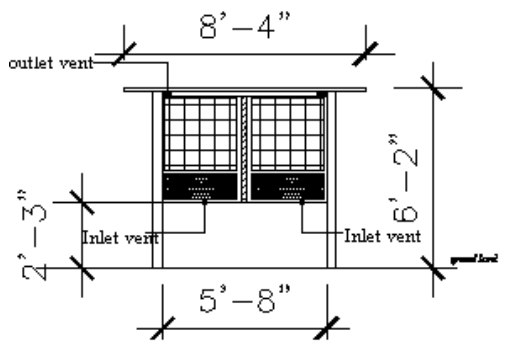

Front View of solar cabinet dryer

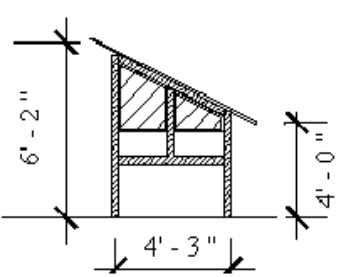

Side view of solar cabinet dryer
Figure 1: Schematics of Solar Cabinet Dryer.

\begin{tabular}{|l|l|l|}
\hline Model & Name & Reference \\
\hline MR $=\exp (-k t)$ & Newton & Liu and Bakker-Arkema (1997) \\
\hline MR $=\exp \left(-k t^{y}\right)$ & Page's & Doymaz (2005) \\
\hline MR $=\exp (-k t)^{y}$ & Modified Page's & Waewsak et al. (2006) \\
\hline MR $=a \exp (-k t)$ & Henderson and Pabis & Waewsak et al. (2006) \\
\hline MR $=a \exp (-k t)+c$ & Logarithmic & Yaldiz et al. (2001) \\
\hline
\end{tabular}

Table 1: Mathematical models as given by various authors.
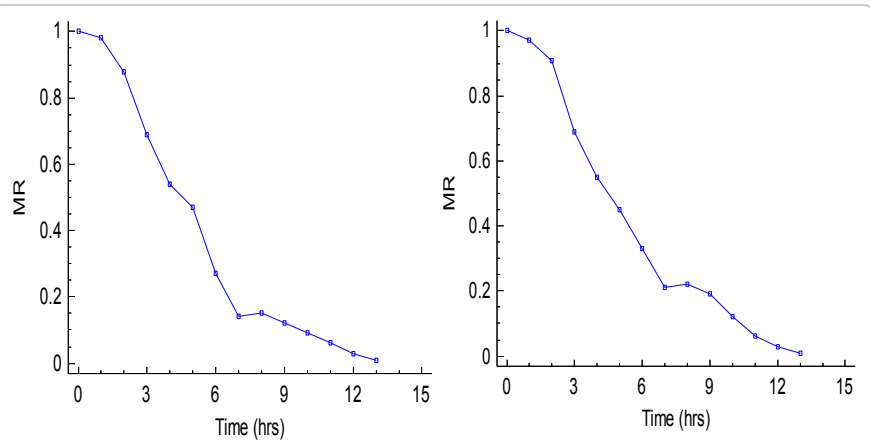

Figure 2: Drying curves for Amaranthus spp and Xanthosoma spp.

\begin{tabular}{|l|c|c|c|c|c|c|}
\hline \multirow{2}{*}{ Model } & \multicolumn{6}{|c|}{ Leafy vegetable } \\
\cline { 2 - 7 } & \multicolumn{4}{|c|}{ Amaranthus spp } & \multicolumn{3}{|c|}{ Xanthosoma spp. } \\
\cline { 2 - 7 } & $r^{2}$ & $R M S E$ & $X^{2}$ & $r^{2}$ & $R M S E$ & $X^{2}$ \\
\hline $\mathrm{MR}=\exp (-k t)$ & 0.9236 & 0.1017 & 0.0100 & 0.9343 & 0.0914 & 0.0084 \\
\hline $\mathrm{MR}=\exp \left(-k t^{\natural}\right)$ & 0.9917 & 0.0349 & 0.0012 & 0.9905 & 0.0363 & 0.0013 \\
\hline $\mathrm{MR}=\exp (-k t)^{y}$ & 0.9236 & 0.1058 & 0.0100 & 0.9343 & 0.0951 & 0.0091 \\
\hline $\mathrm{MR}=a \exp (-k t)$ & 0.9483 & 0.0870 & 0.0070 & 0.9573 & 0.0767 & 0.0058 \\
\hline $\mathrm{MR}=a \exp (-k t)+c$ & 0.9699 & 0.0693 & 0.0046 & 0.9791 & 0.0561 & 0.0033 \\
\hline
\end{tabular}

Table 2: Models and their respective $\mathrm{r}^{2}$, RMSE and $X^{2}$ for Amaranthus spp. and Xanthosoma spp. leaves.

\section{Results and Discussion}

\section{Drying curves}

The drying curves for the two leafy vegetables show a sample heatup period where there is little or no drying. This may probably have been due to low temperatures at the beginning of the drying process, and not actually a sample heat-up period that characterises most drying processes.

The drying curves (Figure 2) show an "elbowing" along the curve, which indicates the period between the discontinuation and resumption of drying. The curves show a very short constant rate period as is observed in the drying of most food products [12] and a longer falling rate period, a phenomenon characteristic of food products with water activity less than 1 [13]. This occurrence demonstrates that diffusion is the dominant physical mechanism governing the removal of moisture from the samples. Similar observations were made by [14] for green beans, [15] for red chilli and [16] for okra.

\section{Mathematical modelling}

The $\mathrm{r}^{2}$, RMSE and reduced chi square values for Amaranthus and Xanthosoma leaves for the chosen models are shown (Table 1). The appropriateness of a model for describing the drying characteristics of samples was based on its $\mathrm{r}^{2}$, RMSE and reduced chi-square. The higher the $r^{2}$ values and lower the reduced $X^{2}$ and RMSE values, the better the goodness of fit [17-21] (Table 2).

All five models showed very good fit with $\mathrm{r}^{2}$ greater than 0.9 (Table 2). For the two samples studied, the Page model resulted in the highest $\mathrm{r}^{2}$ values and corresponding least values for RMSE and reduced chisquare whilst the Newton and Modified Page's models gave the lowest $r^{2}$ and highest RMSE and reduced chi-square. The high $r^{2}$ for the Page model is an indication that it best describes the thin layer solar drying characteristics of the two leafy vegetables and fitted curve for the model is shown in Figure 3. Similar findings were detailed by [22] for [23], 
Citation: Akonor PT, Amankwah EA (2012) Thin Layer Drying Kinetics of Solar-Dried Amaranthus hybridus and Xanthosoma sagittifolium Leaves. J Food Process Technol 3:174. doi:10.4172/2157-7110.1000174

[24] for thin layer drying of diced cassava roots, and [25] for garlic slices.

\section{Effective moisture diffusivity calculation}

A plot of $\ln (\mathrm{MR})$ against time $\mathrm{t}$, gives a line with slope:

$$
\text { Slope }=\frac{\pi 2 D e f f}{4 L 2}
$$

The slope, effective diffusivity values $\left(D_{e f f}\right)$, the corresponding values of coefficients of determination $\mathrm{r}^{2}$ and the reduced chi square $\left(X^{2}\right)$ for the two indigenous leafy vegetables are presented (Table 3) (Figures 4 and 5).

The effective diffusivity, $D_{\text {eff }}$, for the two leafy vegetables are comparable to $6.4 \times 10^{-9} \mathrm{~m}^{2} \mathrm{~s}^{-1}$ as obtained by [26] for drying carrots at $64^{\circ} \mathrm{C}$ and $1.2 \times 10^{-9} \mathrm{~m}^{2} \mathrm{~s}^{-1}-5.9 \times 10^{-9} \mathrm{~m}^{2} \mathrm{~s}^{-1}$, by [27] for carrots dried between 30 and $70^{\circ} \mathrm{C}$. Again it was within the range of $3.8 \times 10^{-10} \mathrm{~m}^{2} \mathrm{~s}$ ${ }^{1}-1.2 \times 10^{-9} \mathrm{~m}^{2} \mathrm{~s}^{-1}$ for drying green pepper at $60-80^{\circ} \mathrm{C}[28]$ and $6.03 \times 10^{-9}$ $\mathrm{m}^{2} \mathrm{~s}^{-1}-3.15 \times 10^{-8} \mathrm{~m}^{2} \mathrm{~s}^{-1}$ for vegetable wastes in a temperature range of $50-150^{\circ} \mathrm{C}$ [27]. At higher drying temperatures, the effective diffusivity is expected to be higher, especially with an increase in the drying air velocity $[28,21,29]$.

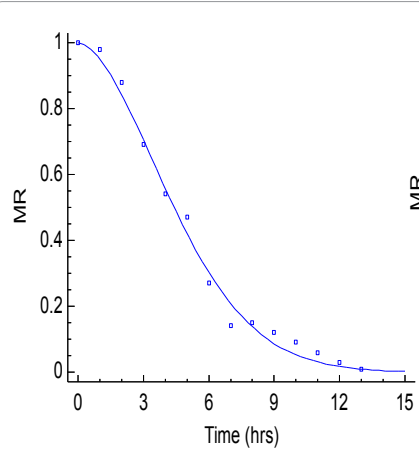

Amaranthus spp

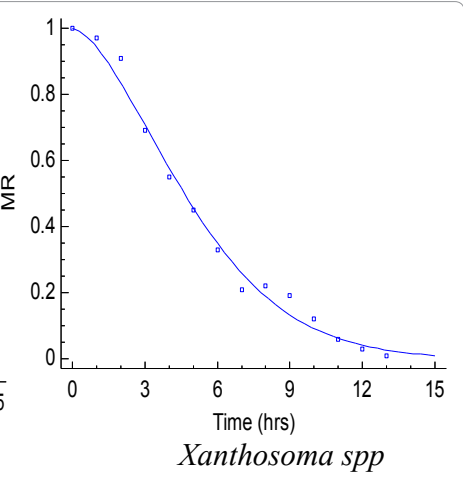

Figure 3: Fitted drying curve for leafy vegetables using Page's model.

\begin{tabular}{|l|c|c|c|c|}
\hline Leafy Vegetable & Slope & $\boldsymbol{D}_{\text {eff }} \mathbf{\times 1 0 ^ { - 9 }} \mathbf{~}^{2} \mathbf{s}^{-1}$ & $\boldsymbol{X}^{2}$ & $\boldsymbol{r}^{2}$ \\
\hline Amaranthus spp & 0.1766 & 1.95 & 0.0200 & 0.9700 \\
\hline Xanthosoma spp & 0.1682 & 2.09 & 0.0086 & 0.9859 \\
\hline
\end{tabular}

Table 3: Effective diffusivity, slope, reduced $X^{2}$ and co-efficient of determination for the leafy vegetables.

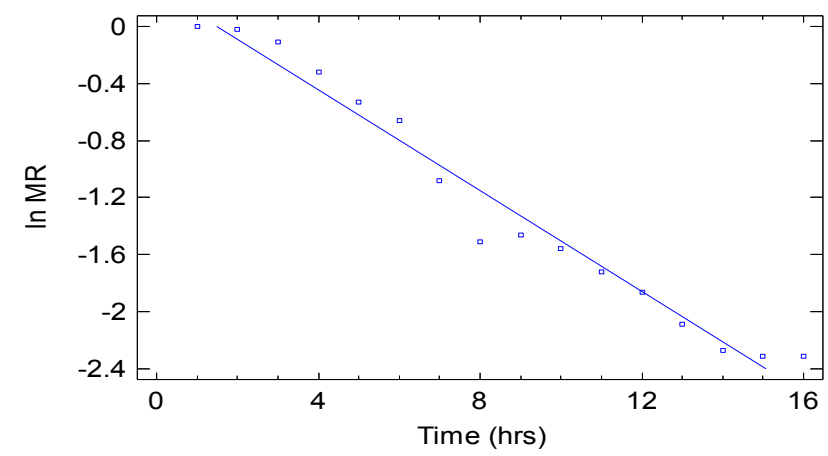

Figure 4: Linear relationship between In MR and drying time for Amaranthus spp.

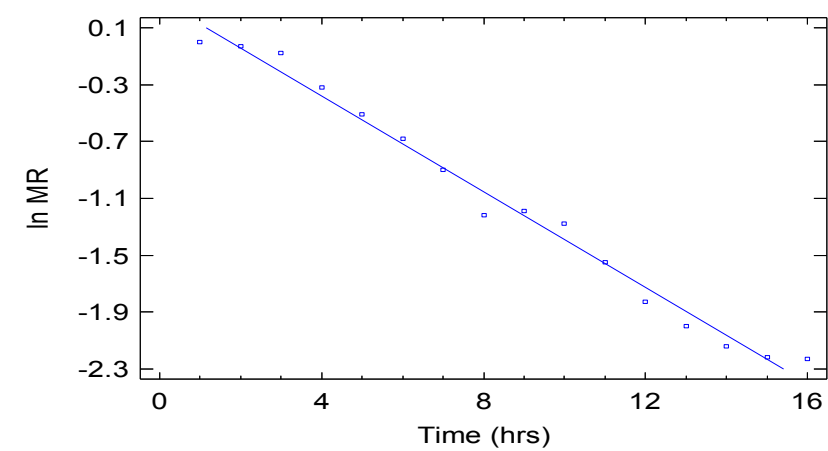

Figure 5: Linear relationship between In MR and drying time for Xanthosoma spp.

\section{Conclusion}

The results show that the change in moisture ratio over time for solar drying the two leafy vegetables can be best described by the Page's model. Under similar drying conditions, the model is appropriate for simulating the outcome of drying these vegetables during process control. Effective Moisture Diffusivity ranged between $1.9 \times 10^{-9} \mathrm{~m}^{2} \mathrm{~s}^{-1}$ and $2.1 \times 10^{-9} \mathrm{~m}^{2} \mathrm{~s}^{-1}$ for the two leafy vegetables.

\section{References}

1. Driscoll R, Smith SJ, Hui YH (2004) Food dehydration - Food Processing: Principles and Applications. Blackwell Publishers 30-42.

2. Jayaraman KS, Das Gupta DK (2006) Drying of fruits and vegetables. In Handbook of Industrial Drying. Mujumder AS (Ed) Taylor and Francis Group LLC.

3. Mudambi SR, Rao SM, Rajagopal MV (2006) Food Science, Rev. (2ndedn) New Age International Publishers Limited, New Delhi. 175.

4. Mujumdar AS (2006) Principles Classification and Selection of Dryers. In Handbook of Industrial Drying, Mujumdar AS (Ed). Taylor and Francis Group LLC.

5. Okos MR, Campanella O, Narsimhan G, Singh RK, Weitnauer AC (2007) Food Dehydration. In: Handbook of Food Engineering, Heldman DR, Lund DB (Eds), CRC Press, Taylor and Francis Group, Boca Raton. 601-743.

6. Nasser H, Sayyad M, Oladegaragoze A (2006) Mathematical Modeling of Thin layer Drying Kinetics of Apple Slices.

7. Helrich K, AOAC (1990) Official Methods of Analysis; Association of Official Analytical Chemists, (15thedn). Arlington, VA

8. Crank J (1975) Mathematics of Diffusion. Oxford UK, Claredon Press

9. Sacilik K (2007) Effect of drying methods on thin-layer drying characteristics of hull-less seed pumpkin (Cucurbita pepo L.). J Food Eng 79: 23-30.

10. Sobukola OP, Dairo OU, Sanni LO, Odunewu AV, Fafiolu BO (2007) Thin layer drying process of some leafy vegetables under open sun. Food Sci Tech Int 13: $35-40$

11. Wang Z, Sun J, Chen F, Liao X, Hu X (2007) Mathematical modeling on thin layer microwave drying of apple pomace with and without hot-air pre drying. $J$ Food Eng 80: 536-544.

12. Hallstrom B, Gekas V Sjoholm I, Romulus AM (2006) Mass Transfer in Food, In: Handbook of Food Engineering, Heldman DR, Lund DB (Eds). CRC Press Taylor and Francis Group.

13. Driscoll R (2004) Food dehydration. In: Food Processing, Principles and Applications. Smith SJ, Yiu HH (Eds), Blackwell Publishers 30-42.

14. Rosello C, Simal S, Sanjuan N, Mulet A (1997) Non Isotropic Mass Transfer Model for Green Bean Drying. J Agric Food Chem 45: 337-342.

15. Gupta P, Ahmed J, Shivhare US, Raghavan GSV (2002) Drying characteristics of Red Chilli. Drying Tech: An Int J 20: 1975-1987. 
Citation: Akonor PT, Amankwah EA (2012) Thin Layer Drying Kinetics of Solar-Dried Amaranthus hybridus and Xanthosoma sagittifolium Leaves. J Food Process Technol 3:174. doi:10.4172/2157-7110.1000174

Page 4 of 4

16. Akgun NA, Doymaz I (2005) Modeling of olive cake thin-layer drying process. J Food Eng 68: 455-461.

17. Ozdemir M, Devres YO (1999) The thin layer drying characteristics of hazelnuts during roasting. J Food Eng 42: 225-233.

18. Ertekin C, Yaldiz O (2004) Drying of eggplant and selection of a suitable thin layer drying model. J Food Eng 63: 349-359.

19. Demir V, Gunhan T, Yagcioglu AK, Degirmencioglu A (2004) Mathematical modeling and the determination of some quality parameters of air-dried bay leaves. Biosystems Eng 88: 325-335.

20. Erenturk S, Gulaboglu MS, Gultekin S (2004) The Thin-layer drying characteristics of rosehip. Biosyst Eng 89: 159-166.

21. Togrul IT, Pehlivan D (2003) Modeling of drying kinetics of single apricot. J Food Eng 58: 23-32.

22. Kajuna STAR, Silayo VCK, Mkenda A, Makungu PJJ (2001) Thin layer drying of diced cassava roots. Afr J Sci Technol 2: 94-100.

23. Madamba PS, Driscoll RH, Buckle KA (1996) The thin-layer drying characteristics of garlic slices. J Food Eng 29: 75-97.

24. Saravacos GD, Charm SE (1962) A study of the mechanism of vegetable and fruit dehydration. Food Tech: An Int J 16: 78-81.

25. Bimbenet JJ, Daudin JD, Wolf E (1985) Air drying kinetics of biologica materials. Drying '85, Mujumdar, A.S., (Ed.), Hemisphere, New York, 178-185.

26. Kiranoudis CT, Maroulis ZB, Marinos-Kouris D (1992) Model selection in air drying of foods. Drying Tech. An Int J 10: 1097-1106.

27. Lopez A, Iguaz A, Esnoz A, Virseda $P$ (2000) Thin-layer drying behaviour of vegetable wastes from wholesale market. Drying Tech: An Int J 18: 995-1006.

28. Park JK, Vohnikova Z, Brod RPF (2002) Evaluation of drying parameters and desorption isotherms of garden mint leaves (Mentha crispa L.). J Food Eng 51: 193-199.

29. Togrul IT, Pehlivan D (2003) Modeling of drying kinetics of single apricot. J Food Eng 58: 23-32. 